Original Research Article

\title{
A study on pattern of adverse drug reaction in an adverse drug reaction monitoring centre of a tertiary care hospital in South Kerala, India
}

\author{
Ajay $\operatorname{Rajan}^{1}$, Ramani P. T. ${ }^{*}$, Sabitha Raj $^{2}$,
}

${ }^{1}$ Department of Pharmacology, Medical College, Trivandrum, Kerala, India

${ }^{2}$ Technical Coordinator, PvPI, Medical College, Trivandrum, Kerala, India

Received: 22 May 2019

Accepted: 06 July 2019

*Correspondence to:

Dr. Ramani P. T.,

Email: talk2thanu@gmail.com

Copyright: (C) the author(s), publisher and licensee Medip Academy. This is an openaccess article distributed under the terms of the Creative Commons Attribution NonCommercial License, which permits unrestricted noncommercial use, distribution, and reproduction in any medium, provided the original work is properly cited.

\begin{abstract}
Background: Adverse drug reactions (ADR) are rated as fifth leading cause of death and accounts for approximately $5 \%$ of all hospital admissions. Under reporting of ADR from healthcare professional is considered as the contributing factor for increased morbidity and mortality. India has taken well appreciated step to launch Pharmacovigilance Programme of India (PvPI) to safeguard heath care of Indian population. This study looks into the detailed analysis of ADR reported to adverse drug reaction monitoring centre (AMC), Government Medical College, Trivandrum to assess its pattern, causality, severity and seriousness of ADR. Primary objectives of this study are the pattern of adverse drug reactions reported to ADR monitoring centre (AMC) and secondary objective is to assess causality, severity.
\end{abstract}

Methods: A record based descriptive study was conducted in the ADR monitoring centre of government medical college, Trivandrum, Kerala from September $1^{\text {st }} 2016$ to February 2017(6 months). The data were collected from the all reported case records/ ADR report form of CDSCO. The details of the various adverse drug reactions were identified and analysed to find the pattern of adverse drug reactions including distribution of age, gender, causal drug group, system organ class. Also, an attempt is made to do causality assessment using WHO UMC scale and severity by using Heart wig Seigel Scale.

Results: Out of 320 ADR cases, majority of reports were due to cutaneous manifestations. Most common ADRs were erythema, induration, and rash, itching. Females were $56 \%$ and males were $44 \%$. Majority cases were of adult age group. Causality $91.88 \%$ were probably related, $75.6 \%$ were mild reaction. $25 \%$ of cases were serious. $77.5 \%$ were recovered. Antibacterial implicated 25(7.8\%) followed by anti-epileptics $24(7.5 \%)$ ADR.

Conclusions: The pattern of adverse drug reactions reported to this AMC is comparable to the studies done in other parts of country. A strong need for streamlining of ADR monitoring system and reporting reemphasized by this study, which will promote the ADR reporting in healthcare professionals.

Keywords: ADRs, AMC, ADR Pattern, Causality, Outcome, PvPI, Severity

\section{INTRODUCTION}

Adverse drug reactions (ADR) are rated as fifth leading cause of death and accounts for approximately $5 \%$ of all hospital admissions. ${ }^{1}$ As per WHO, Adverse drug reaction is 'any noxious change which is suspected to be due to a drug, occurs at doses normally used in man, requires treatment or decrease in dose or indicates caution in the future use of the same drug'. ${ }^{2}$ Pharmacovigilance is defined by World Health Organization as "the science and activities relating to the detection, assessment, understanding and prevention of adverse effects or any other possible drug-related problems"2. 
It is one of the indispensable steps taken by Ministry of Health and Family Welfare, Government of India for ensuring rational and safe use of medicine. This program was launched nation-wide in July 2010. The mission of pharmacovigilance program of India (PvPI) is to safeguard the health of Indian population by ensuring that the benefit of use of medicine outweighs its risk. Since there is a considerable social and economic impact due to adverse drug reactions there is a need to engage each and every healthcare professionals and the public in this country for close monitoring of adverse drug reaction. ${ }^{3}$

Pharmacovigilance centres have been set up in most countries. The Uppsala Monitoring Centre (Sweden) is the international collaborating centre. Indian Pharmacopoeia Commission (IPC) at Ghaziabad functions as National Coordinating Centre (NCC) for PvPI. Main responsibility of NCC is to monitor all ADRs of medicine being used in Indian population and to develop and maintain its own pharmacovigilance database for patient safety, so that regulatory intervention can be done. ${ }^{3}$ There are four regional centres under PvPI, and they are expected to give training and technical supports to the newly enrolled AMCs and all other stakeholders under PvPI. ${ }^{3}$ ADR monitoring centres (AMCs) are the corner stone of PvPI. ${ }^{3}$ They are located in medical colleges and other institutes including peripheral hospitals.

They are expected to collect individual case safety reports and to provide expertise for assessing causality and severity of ADRs by using standard algorithms and rating scales. $^{2}$ In Kerala there are 9 AMCs. ${ }^{4}$ Department of pharmacology government medical college Trivandrum has been recognized as adverse reaction monitoring centre since 2014 under PvPI. We are coordinating the pharmacovigilance activities in the state. The suspected ADRs were diagnosed by the treating physician of various clinical departments. Authors are receiving details of ADR in spontaneous ADR reporting form from various clinical departments of our institute and other hospitals. We first verify the report, and send through 'vigiflow' software to NCC, IPC Ghaziabad. Simultaneously we enter ADR data in the Microsoft excel sheet. In addition to this we are conducting awareness programs on pharmacovigilance activities for doctors and health professionals of various clinical specialities.

Despite the progress that has been made in pharmacovigilance, the burden on public health of adverse reactions to medicines (traditionally referred to as ADRs) remains significant. Pharmacoeconomic studies on the costs of ADRs suggest that governments pay considerable amounts from their health budgets towards covering the costs associated with them. ${ }^{5}$ Under reporting of ADR from health professionals is another big problem. Through this study authors attempt to produce a detailed analysis of various patterns of ADRs using available data in this AMC. Also, in the study an attempt is made to assess causality and severity of ADR reported. This consolidated data can be used to educate health care professionals regarding various aspects of recently reported ADRs and presented to the policy makers to produce required regulatory steps. We hope this study will definitely give more insight in to various issues related to ADRs and thus helpful in strengthening the pharmacovigilance program in the country. And we hope this study will have the advantages in the following perspectives,

- In Physician perspective, they will be more updated on ADRs, which will help them in safe and judicious use of drugs for better care of their patients.

- In patient perspective, drug compliance will be improved due to less ADR, and hence overall cost of treatment can be reduced and hence better quality of life can be ensured.

\section{METHODS}

A record based descriptive study was conducted in the ADR monitoring centre of government medical college, Trivandrum, Kerala from September $1^{\text {st }}, 2016$ to February 2017(6 months). After obtaining clearance from Institutional Research Board (IRB) and Institutional Ethics Committee (IEC) the data were collected from the all reported case records/ ADR report form of CDSCO in the ADR monitoring centre of Government Medical college, Trivandrum during the period of September 2016 to February 2017. Study population was, all case reported to ADR monitoring centre of Government Medical College, Trivandrum

\section{Inclusion criteria}

- Cases which occurred in Government Medical College, Trivandrum.

- Cases reported from September 2016 to February 2017.

\section{Exclusion Criteria}

- Cases which occurred outside Government Medical College, Trivandrum.

The details of the various adverse drug reactions were identified and analysed to find the pattern of adverse drug reactions including distribution of age, gender, causal drug group, system organ class. Also, an attempt is made to do causality assessment using WHO UMC scale and severity by using Heart wig Seigel Scale.

\section{Statistical analysis}

Data entered in Microsoft excel software and proportions were calculated.

\section{RESULTS}

In this study period our AMC have received 320 ADR cases from various specialities of our hospital, majority of reports were due to cutaneous manifestations. All cases 
were analysed for system organ class, various classes of drugs, causality, severity, outcome and seriousness. A high occurrence of ADR was seen in females $(56 \%)$ compared to males (44\%) and male: female ratio according to ADR occurrence was 0.78 (Figure 1). Majority cases (62.2\%) were of adult age group (between 18 and 60 years). $57(17.8 \%)$ paediatric patients i.e. 18 years and below experienced ADRs and 64(20\%) geriatric patients i.e. 60 years and above experienced ADRs (Table 1).

Table 1: Demographic status of patients.

\begin{tabular}{|ll|}
\hline Characteristics & Frequency $(\%)$ \\
\hline Male & $140(43.8)$ \\
\hline Female & $180(56.2)$ \\
\hline Paediatric & $57(17.8)$ \\
\hline Adult & $199(62.2 \%)$ \\
\hline Geriatric & $64(20 \%)$ \\
\hline
\end{tabular}

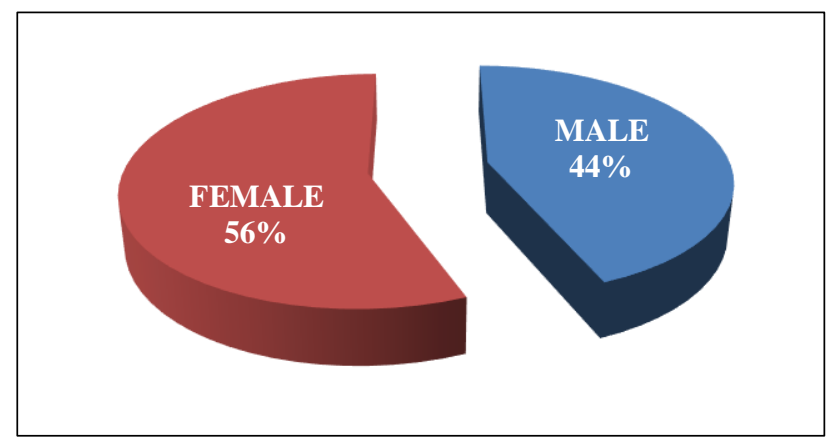

Figure 1: Gender distribution of ADR.

The causality (Figure 2) was assessed for all 320 cases using WHO-UMC scale.

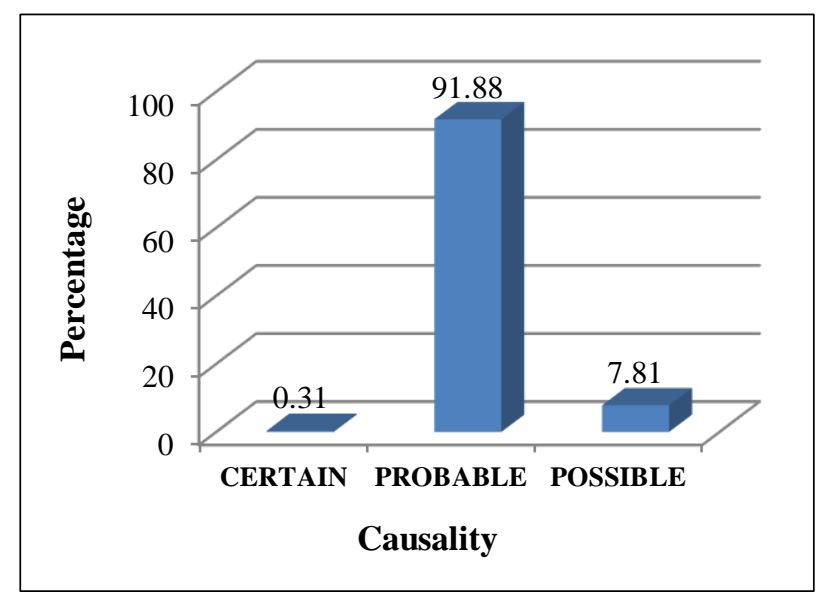

Figure 2: Distribution of ADR according to Causality.

Most of the ADR reported during study period were probably related $(91.88 \%)$, possibly related were $7.8 \%$ and certainly related were $0.31 \%$. Regarding the severity (Figure 3) of ADR, 75.6\% were mild, $22.5 \%$ were moderate and $1.9 \%$ were severe. $80(25 \%)$ out of 320 cases were considered serious (Figure 4) as they required hospitalisation, or it was a life-threatening event. The remaining $240(75 \%)$ were non-serious and treated on outpatient basis. There was no death due to ADR during this study period. Analysis of frequency of ADR reported during study period based on various outcome (Figure 5) categories shows that most of the reactions came under recovered category $(77.5 \%)$, and not recovered were only $3.12 \%$ (Table 2).

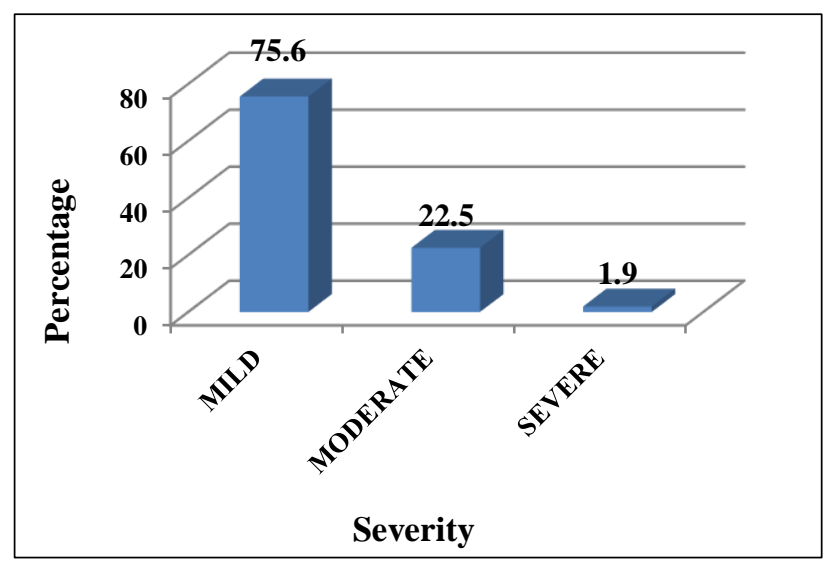

Figure 3: Distribution of severity of reported ADRs.

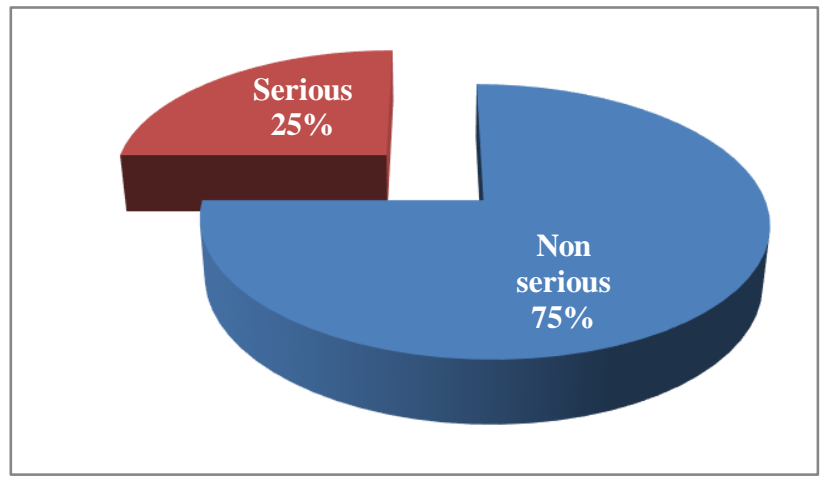

Figure 4: Distribution of seriousness of reported ADRs.

Table 2: Percentage distribution of ADR Parameters.

\begin{tabular}{|lll|}
\hline Parameter & & $\mathbf{N}(\boldsymbol{\%}),(\mathbf{n}=\mathbf{3 2 0})$ \\
\hline \multirow{3}{*}{ Causality } & Certain & $1(0.31)$ \\
\cline { 2 - 3 } & Probable & $294(91.88)$ \\
\cline { 2 - 3 } Severity & Possible & $25(7.81)$ \\
\hline \multirow{3}{*}{ Seriousness } & Mild & $242(75.6)$ \\
\cline { 2 - 3 } & Moderate & $72(22.5)$ \\
\cline { 2 - 3 } & Severe & $9(1.9)$ \\
\hline \multirow{3}{*}{ Outcome } & Non-Serious & $240(75)$ \\
\cline { 2 - 3 } & Hospitalization & $6(1.9)$ \\
\cline { 2 - 3 } & Recovered & $74(23.1)$ \\
\cline { 2 - 3 } & Recovering & $248(77.5)$ \\
\cline { 2 - 3 } & Not Recovered & $6(18.75)$ \\
\hline
\end{tabular}


If we exclude mild reaction (erythema and induration) caused by immunoglobulin and vaccines on giving test dose, major class of drugs that caused ADR was antibacterial $(25,7.8 \%)$ followed by anti-epileptics $(24$, $7.5 \%)$. In the antibacterial anti TB drugs $(20 \%)$ and in antiepileptics' phenytoin (75\%) produced highest number of reactions. In the organ system class affected, skin and subcutaneous system including administration site reaction $(88.12 \%)$ were most common followed by gastrointestinal system including hepatobiliary, and next affected was nervous system.

Table 3: System organ class affected.

\begin{tabular}{|l|l|}
\hline System organ class & $\begin{array}{l}\text { Frequency } \\
(\%)\end{array}$ \\
\hline $\begin{array}{l}\text { Skin and subcutaneous tissue disorders, } \\
\text { administration site reaction. }\end{array}$ & $282(88.12)$ \\
\hline Gastrointestinal disorders & $3(0.94)$ \\
\hline Hepatobiliary disorders & $14(4.38)$ \\
\hline Nervous system disorders & $11(3.44)$ \\
\hline Renal and urinary disorders & $1(0.31)$ \\
\hline Blood and lymphatic system disorders & $1(0.31)$ \\
\hline Cardiac disorders & $1(0.31)$ \\
\hline $\begin{array}{l}\text { Respiratory, thoracic and mediastinal } \\
\text { disorders }\end{array}$ & $1(0.31)$ \\
\hline $\begin{array}{l}\text { Musculoskeletal and connective tissue } \\
\text { disorders }\end{array}$ & $1(0.31)$ \\
\hline General disorders & $2(0.63)$ \\
\hline Anaphylaxis & $3(0.94)$ \\
\hline Total & $320(100)$ \\
\hline
\end{tabular}

Table 4: Classes of suspected drugs.

\begin{tabular}{|lll|}
\hline No & Class of drugs & Frequency(\%) \\
\hline 1 & Antibacterial & $25(7.8)$ \\
\hline 2 & Antiepileptic & $24(7.5)$ \\
\hline 3 & Antipsychotic & $3(0.9)$ \\
\hline 4 & Antiplatelet & $1(0.3)$ \\
\hline 5 & Immunoglobulins & $177(55.3)$ \\
\hline 6 & Anticancer & $6(1.9)$ \\
\hline 7 & Diuretic & $3(0.9)$ \\
\hline 8 & NSAIDs & $12(3.8)$ \\
\hline 9 & Ayurvedic Preparations & $4(1.3)$ \\
\hline 10 & Vaccines & $54(16.9)$ \\
\hline 11 & Beta-blockers & $1(0.3)$ \\
\hline 12 & Antidepressants & $1(0.3)$ \\
\hline 13 & NAC & $1(0.3)$ \\
\hline 14 & Antidiabetic & $1(0.3)$ \\
\hline 15 & Hypolipidemic & $1(0.3)$ \\
\hline 16 & Steroids & $1(0.3)$ \\
\hline 17 & Antiarrhythmics & $1(0.3)$ \\
\hline 18 & Antiviral & $1(0.3)$ \\
\hline 19 & Antithyroid & $1(0.3)$ \\
\hline 20 & Antidiarrheal & $1(0.3)$ \\
\hline 21 & Antifungal & $1(0.3)$ \\
\hline & Total & $320(100)$ \\
\hline
\end{tabular}

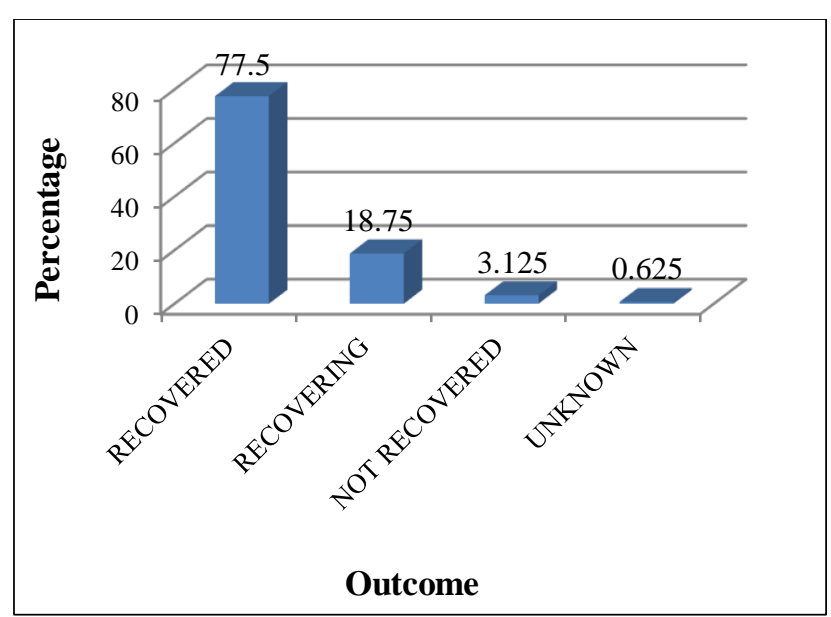

Figure 5: Distribution of various outcome of ADRs.

Adverse drug reactions of some of the commonly seen drugs were given in the appendix 1 . Most common ADRs were erythema, induration, and rash, itching (Table 3, 4, Appendix 1).

\section{DISCUSSION}

Adverse drug reaction (ADR) can cause considerable amount of morbidity and mortality with an increase in the medical expenses. ${ }^{6}$ ADR can be considered as a differential diagnosis of variety of conditions, as it is difficult to diagnose. ${ }^{7}$ In General Practice consultations around $3 \%$ and in unscheduled hospital inpatients around $6 \%$ were found to be due to ADRs. ${ }^{7}$ In the present study we evaluate the pattern of the ADRs and tried to assess causality, severity, seriousness and outcome.

As per a recent study done in a private hospital in South India, ADR incidence was found to be $1.8 \%$, which means around 2 cases per 100 patients. ${ }^{8}$ In this study a total of 320 ADR cases were reported to our AMC in 6 months.

In this study $56 \%$ of cases reported were females and $44 \%$ were male with, male-Female ratio of 0.78 . In a study done in a teaching hospital in India shows similar result, out of the total cases reported females were more compared to males. ${ }^{6}$ In this study mean age of patients reported with ADRs was $40.41 \pm 1.14$ years (mean \pm standard error of mean) (95\% confidence interval, 38.18-42.64 years). And regarding the age distribution Out of 320 cases reported, majority belongs to the age group 18-60 (62.2\%), paediatric and elderly cases were less. In a similar study. ${ }^{6}$ done in teaching hospital of south India, most common age group of ADR cases were between 18 and 59 years (73.33\%). Analysis of frequency of distribution of ADR reported during study period based on various causality categories (Figure 2) shows that most of the reactions came under "probable" category $91.88 \%$, and "certain" category was $0.31 \%$.

Regarding the severity of ADR (Figure 3), 75.6\% were mild, $22.5 \%$ were moderate and $1.9 \%$ was severe. As per 
Nebeker JR et al, and Guenka Petrova et al, life threatening and hospitalisation were included in serious category. ${ }^{12}$ Table 2 and Figure 4 shows that out of 320 cases of ADR reported during the study period 80 were serious with an occurrence rate of $25 \%$ in which threatening cases reported were $6(1.9 \%)$. A recent study also showed a low number in the serious category, i.e. only $7(9.33 \%)$ out of 75 reactions were considered serious in that study. ${ }^{9}$

In this study recovering and recovered together comes around $96.25 \%$ (Figure 5). A recent study done in south India also showed similar result, in that study, most patients $(72.6 \%)$ were recovered from the incidence. ${ }^{10}$ Analysis of frequency of ADR reported during study period based on various system organ classes (Table 3) shows that most of the reactions came under skin and subcutaneous disorder including administration site reaction $(88.12 \%)$, followed by hepatobiliary system $(4.38 \%)$ and nervous system $(3.44 \%)$. Skin and subcutaneous ADRs findings were comparable with an international study. ${ }^{11}$ Regarding the distribution of different classes of drugs (Table 4) causing ADR, immunoglobulin was the most common class of drugs $(55.3 \%)$ followed by vaccines $(16.9 \%)$. Other common class of drugs reported were due to antibacterial $(25,7.8 \%)$, and antiepileptic $(24,7.5 \%)$. In one previous study antibacterial, and antiepileptic were shown as most implicated drug classes. ${ }^{11}$

\section{CONCLUSION}

The pattern of adverse drug reactions reported to this ADR Monitoring Centre is comparable to the studies done in other parts of country. It gives a database of commonest drugs prescribed in this hospital, and this will help the clinicians for the optimum and safe use of commonest drugs used in this hospital. In this study adverse drug reactions reported were commonly due to antimicrobials and antiepileptic, if we exclude mild administration site reaction due to immunoglobulin and vaccines. And the most of the suspect ADR reported in the causality category of probable or possible. The commonest organ system affected was skin and cutaneous system. A strong need for streamlining of ADR monitoring system and reporting reemphasized by this study, which will promote the ADR reporting in the healthcare professionals.

\section{ACKNOWLEDGEMENTS}

We greatly acknowledge National Co-ordination CentrePharmacovigilance programme of India, Indian Pharmacopoeia Commission, Ministry of health and family welfare for providing training and technical support to our team in AMC.

Funding: No funding sources Conflict of interest: None declared

Ethical approval: The study was approved by the Institutional Ethics Committee

\section{REFERENCES}

1. Verma R, Vasudevan B, Pragasam V. Severe cutaneous adverse drug reactions. Med J Armed Forces India. 2013 Oct; 69(4):375-83.

2. K D Tripathi, Adverse drug effects, K D Tripathi, Essentials of medical pharmacology by Jaypee brothers' medical publishers (p) ltd, $7^{\text {th }}$ ed. New Delhi; 2013: 82 .

3. Indian Pharmacopoeia Commission, Ministry of Health and Family Welfare, Government of India [Internet]. Available at: http://www.ipc.gov.in/. Accessed 26 Sep 2017.

4. Indian pharmacopoeia commission, ADR reporting [internet]. Indian pharmacopoeia commission government of India, pharmacovigilance government of India. 2016. Available at: http://www.ipc.gov.in/PvPI.

5. Organization World Health, The safety of medicines in public health programmes: pharmacovigilance, an essential tool. 2006; Available at: http://apps.who.int/iris/bitstream/10665/43384/1/924 1593911_eng.pdf. Accessed 26 Sep 2017.

6. Gaur S, Paramjeet S, Srivastava B, Bhardwaj R, Ahuja S, Gunjita B. Evaluation of adverse drug reactions in teaching hospital in Kumoun region. JMSCR. 2016;4:12139-45.

7. Ferner RE. Adverse drug reactions. Medicine. 2016 Jul 1;44(7):416-21.

8. Sriram S, Ghasemi A, Ramasamy R, Devi M, Balasubramanian R, Ravi TK, et al. Prevalence of adverse drug reactions at a private tertiary care hospital in south India. J Res Med Sci. 2011 Jan;16(1):16-25.

9. Swamy S, Bhanuprakash NP, Muralimohan SM. Profile of suspect adverse drug reactions in a teaching tertiary care hospital. J Pharmacol Clin Toxicol. 2013;1(1):1005.

10. Arulmani R, Rajendran SD, Suresh B. Adverse drug reaction monitoring in a secondary care hospital in South India. Br J Clin Pharmacol. 2008 Feb; 65(2):210-6.

11. Suh DC, Woodall BS, Shin SK, Hermes-De Santis ER. Clinical and economic impact of adverse drug reactions in hospitalized patients. Ann Pharmacother. 2000 Dec; 34(12):1373-9.

12. Petrova G, Stoimenova A, Dimitrova M, Kamusheva M, Petrova D, Georgiev O. Assessment of the expectancy, seriousness and severity of adverse drug reactions reported for chronic obstructive pulmonary disease therapy. SAGE open medicine. 2017 Jan $31 ; 5(1)$.

Cite this article as: Rajan A, Ramani PT, Raj S. A study on pattern of adverse drug reaction in an adverse drug reaction monitoring centre of a tertiary care hospital in South Kerala. Int J Basic Clin Pharmacol 2019;8:1813-8. 


\section{APPENDIX-1}

\begin{tabular}{|c|c|}
\hline Drug & Adverse Reaction (Frequency) \\
\hline Amiodarone & Liver injury (1) \\
\hline $\begin{array}{l}\text { Amitryptiline plus } \\
\text { methylcobalamine }\end{array}$ & $\operatorname{SJS}(1)$ \\
\hline Amoxicillin & Toxic Epidermo Necrolysis (1), Angioedema (1) \\
\hline Amoxycillin + clavulanate & Maculopapular exanthema(1) \\
\hline Ampicillin & Exanthema (1) \\
\hline Aripiprazole & Akathesia (1) \\
\hline Anti-snake venom & Itching(1) \\
\hline Atorvastatin & Myopathy(1) \\
\hline Anti TB treatment & Liver injury (3) exfoliative dermaititis (1) Itching (1) \\
\hline Azithromycin & Hypersensitivity (1) Itching (1) \\
\hline Azathioprine & Liver injury (1) \\
\hline Carbamazepine & Maculopapular exanthema (1) Maculopapular rash (1) \\
\hline Ceftriazone & Delirium(1) \\
\hline Cefuroxime & Maculopapular exanthema (1) Mucositis (1) \\
\hline Ciprofloxacin & Fixed drug eruption (1) photodermatitis (1) \\
\hline Clozapine & Anaemia (1) \\
\hline Crystalline penicillin & Itching (1) \\
\hline Diclofenac & Itching (1) erythema (1) wheal (1) \\
\hline Piroxicam & Pemphigus vulgaris (1) \\
\hline Doxirubicin & Alopecia (1) \\
\hline DTP Vaccine & Febrile seizure (2) \\
\hline Aspirin & Angioedema \\
\hline Phenytoin & $\begin{array}{l}\text { Steven Johnson syndrome (3) Toxic Epidermo Necrolysis (1) Maculopapular exanthema (4) Drug } \\
\text { Hypersensitivity Syndrome (2) Maculopapular rash (3) Exfoliative dermatitis (2) ataxia (1) itching (1) } \\
\text { rash (1) }\end{array}$ \\
\hline Ibuprofen & Gastrointestinal ulcer (1) \\
\hline Cetriaxone & Fatigue (1) \\
\hline Ciprofloxacin & Itching (1) \\
\hline Lamotrigine & Steven Johnson syndrome (1) \\
\hline Furosemide + Spironolactone & Rash (1) kidney injury (1) altered sensorium (1) \\
\hline Thalidomide & Rash (1) \\
\hline Levetriacetam & Itching (1) \\
\hline Levofloxacin & Itching (1) \\
\hline Levofloxacin & Angioedema (1) \\
\hline Cefixime & Oral lesion (1) \\
\hline Mefenamic Acid & SJS TEN (1) anaphylaxis (1) FDE (1) Gibleed (1) \\
\hline Meropenem & Exanthema (1) \\
\hline Metformin & Liver injury (1) \\
\hline Methotrexate & SJS (1) \\
\hline Methyl Prednisolone & Breathing difficulty (1) \\
\hline Mycophenolate mofetil & Liver injury (1) \\
\hline Amoxycillin + Clavulanic acid & SJS TEN (1) \\
\hline N Acetyl Cysteine & Itching (1) \\
\hline Naproxen & Hematemisis (1) \\
\hline Olanzapine, & Tremor (1) \\
\hline Paracetamol & SJS TEN (2) \\
\hline Penicillin & Fatigue (1) \\
\hline Propranolol & Brady cardia (1) \\
\hline Propylthiouracil & Liver injury (1) \\
\hline Tegrital & Maculopapular exanthema (1) \\
\hline Tenofovir & Liver injury (1) \\
\hline Vincristine & Liver injury (1) \\
\hline Pentavalent Vaccine & Febrile seizure (4) \\
\hline
\end{tabular}

